\title{
Efficiency of Fabric Repellency to Mosquitoes
}

\author{
Rasha Sameer Mohammad Mujallid \\ Department of Home Sciences Education, Al-Lith College, Umm Al-Qura University, Mecca, KSA \\ Email: rashamu0@gmail.com
}

How to cite this paper: Mujallid, R. S. M. (2019). Efficiency of Fabric Repellency to Mosquitoes. Art and Design Review, 7, 175-186.

https://doi.org/10.4236/adr.2019.74015

Received: October 17, 2018

Accepted: September 7, 2019

Published: September 10, 2019

Copyright $\odot 2019$ by author(s) and Scientific Research Publishing Inc. This work is licensed under the Creative Commons Attribution International License (CC BY 4.0).

http://creativecommons.org/licenses/by/4.0/

(c) (i) Open Access

\begin{abstract}
Textile finishing sectors had a great development, and health awareness is increasing, the finishing of textile to repel insect is very important and urgent to prevent transmission of mosquitoes diseases. Therefore, the researcher found that the Neem tree can be used in textile finishing as repel mosquitoes, by using the solution extracted from green and dry Neem leaf for future applications, in apparel industry, tents, curtains and furnishings. This research used the experimental descriptive method, which describes the phenomenon, summarizes data and information to analyze it for conclusion and recommendation. The researcher surveyed data and information about the neem tree and used it for textile finishing as repel insects, some properties of textile were tested to evaluate the effect of solution extracted from green and dry leaf of Neem tree on the performance of textile properties and repel insects. It was found that the fabric finished by using green Neem leaf, has the ability to repel $80 \%$ of mosquitoes, and the fabric finished by using dry Neem leaf, has the ability to repel $60 \%$ of mosquitoes, and the finishing of fabric with the extracted solution green and dry Neem leaf has a significant effect on the fabric properties.
\end{abstract}

\section{Keywords}

Textile Finishing, Efficiency, Mosquitoes, Neem Tree

\section{Introduction}

In line with the improvement of people's living standard and the growing awareness and need to preserve the environment, several regulations were introduced, also in the textile industry in order to control the use of chemicals in textile processes and use natural material for textile finishing.

Due to the severity of diseases, which transmitted by Mosquitoes, great efforts have been done to search new treatment of textile based on plant to be more effective and safe for fighting Mosquitoes instead of insecticides that gain the 
mosquitoes immunity, in addition, the insecticides are high toxicity.

Mosquitoes are one of the worst enemies for humans and animals and are considered the first enemy of the harmful insects to transmit many diseases between people a year such as malaria fever, dengue fever, rift valley fever, and other diseases.

The progress and development in the textile sectors lead to finish the textiles to be repelling insects by using natural plants.

Neem trees contain many compounds, the Salannun compound is one of them and has significant effect to be insect repellent, especially against mosquito, and many compounds were extracted from Neem seeds and leaf, and were used as natural insecticides, insect repellent that affected on some kinds of insects, mites and worms.

Neem extracted for insect repelling is antibacterial, some studies recommended for more researches on the plants to apply on the textile finishing and treatment to improve the textile finishing, being an alternative of harmful chemicals treatments.

\section{Review of Literature}

Due to the increment of awareness of green environment, the requirements of consumers for apparel to be healthy, environmentally friendly. The idea of eco-friendly clothing is to develop the product from raw materials to the recycling for healthy and clean environment.

All processes of apparel production as fiber, spinning, weaving, finishing, treatments, readymade garment, and recycling must be friendly for environment, also the materials used for apparel manufacturing must be recycled and reuse again to be eco friendly and for sustainability to save the sources of new raw materials (Nassif, 1999).

In many studies, the researchers have focused to produce fabric with specials treatments as, anti bacteria, anti mold, insect repelling, oil repellency and flame resistance, etc. (Sheta \& Nader, 1999).

Despite of the great importance of the finishing processes for textile to meet the requirements of textile sector, as expansion, the ability to compete in domestic and international markets to add high value, most of the studies have shown that the manufacture of wet processing for textile is one of the largest sources of pollution in the textile sector. More than 300 to 800 different types of chemicals items are used, most of them do not have safety data sheet (Nassif \& Okda, 2004).

So the researchers interested of nature, where they found more facilities that could be helpful for new modern technologies.

"Biomimetic Nature" has become the focus of the researchers, using this simulation technique to understand the natural structures for its applications, because the nature is the first teacher of human for inventions.

The research of Hatem et al. (2011) evaluated the efficiency of water extracts and dry powders of some plants as Oak, Eucalyptus, Civet and Sorrel on some 
aspects of fly insect, the water extract showed the rate of mortality of fly insects between $51.1 \%$ and $78.8 \%$. Also deformities of the appearance and reduction of the weight of larva, in other sides the dry powder had a significant effect on the rate of mortality of the house fly.

Girish and Shankara Bhat (2008) have named the Green Treasure on the Neem because of its multiple of applications.

Neem belongs to the family Meliaceae, subfamily Meloideae and tribe Melieae. Neem is the most versatile, multifarious trees of tropics, with immense potential. It possesses maximum useful non-wood products (leaf, bark, flowers, fruits, seed, gum, oil and Neem cake) than any other tree species. These non-wood products are known to have antifungal, antipyorrhoeic, antiscabic, insecticidal, larvicidal, and other biological activities.

Because of these activities of Neem, it has found enormous applications making it a green treasure (Girish \& Shankara Bhat, 2008).

Neem tree was introduced in places such as Australia, East and sub-Saharan Africa, South East Asia, and South America. Today, the neem is well established in at least 30 countries worldwide, in Asia, Africa and Central and South America. Some small scale plantations are also reportedly successful in Europe and United States of America (Qaisi, 1998).

Neem is a multipurpose agro forestry tree that is well adapted to a wide range of climatic, soil conditions, and has gained worldwide recognition for its pharmaceutical and pesticides properties. The world's largest pure Neem plantations are available in the plains of Arafat, Saudi Arabia where thousands Neem trees were planted to provide shade from the blazing summer sun for the millions of Hajis (Muslim pilgrims).

Mature Neem trees are found in Medinah, Taif and elsewhere of the Kingdom of Saudi Arabia (Mridha \& Al-Suhaibani, 2014).

Figure 1 shows that in the Kingdom of Saudi Arabia, there are about more than one hundred thousand tree of Neem, distributed around the holy sites between

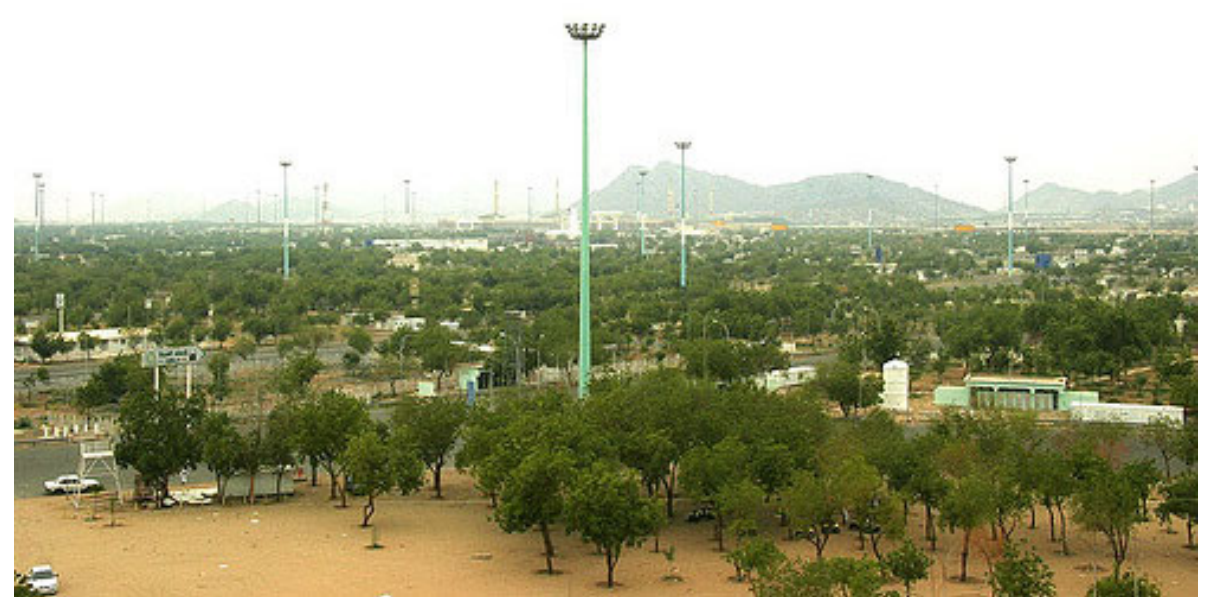

Figure 1. Neem plantation on plains of Arafat in Makkah, Kingdom of Saudi Arabia. 
Makkah and Arafat. They are planted in order to provide the shade, comfort for about two million pilgrims, also there are Neem trees in other regions which has hot climate in the Kingdom of Saudi Arabia (Abu Abdoun, 2000).

The Indian people are the first human to use all parts of tree Neem, as leaf, bark, seed and branches of their medical uses. They extracted oils as natural compounds, which proved health benefits, the flowers of Neem release an aromatic smell which is good for human and is repel for the insects (Michel, 1993).

Neem plants have affect against great groups of insects and are not only specialized to treat a particular insect but also the extracted Neem has efficacy against 60 kinds of insects when used with very low concentrations, as the study which carried out in US universities, it has affect against the white fly that infects sweet potatoes, and snaky worm.

Alouani et al. (2009) studied the effect of Azadirachtin as natural pesticides, which extracted from the Neem tree on the Larvae and virgin of Mosquito, in this study the rate of Fertility decreased and the female infertility increased, the study recommended using the Neem as natural pesticide instead of chemical pesticides.

Al-Mohmadi, and Al-Khalef (2008) found that the deactivation of egg production and mosquito repellent, depended on the concentration of the plant extract. In addition to the possibility of Neem extract for insect repelling, it is also antibacterial. Thilagavath et al. (2005) proved that the neem is $100 \%$ antibacterial, the study recommended for more researches on the plants to apply on the textile finishing and treatment to improve the washing fastness, also to be an alternative of harmful chemicals treatments.

The researchers are inspired by their patents and innovations from Nature, which offers multiple means that can be invested to improve the end use of the smart textile.

\section{The Aim of the Research Are as the Following}

1) Application the extracted solution from green and dry Neem leaf on textile finishing.

2) Evaluation the textile finishing, by using the extracted green and dry Neem leaf.

3) Evaluation the effect of the solution extracted from green and dry Neem on the textile properties as (Weight, thickness, hardness, drapeability, air permeability, and crease recovery).

\section{Experimental of Work}

\subsection{Preparation the Extracted Solution from Green Neem Leaf}

The Neem leaf samples were collected from the area of Arafat, Makkah, Saudi Arabia, and were packed in plastic bags and were transported to the Textile Laboratory, University of Umm Al Qura. Leaf samples were washed using water to remove dust and particles. The leaves were separated from the stalk, the leaves 
were kept in plastic bag.

The Neem leaves were covered with water at a ratio of one kilogram of leaves to five liters of water, and soaked over night without heat or boil to get high concentration of Azadirachtin content. After that the leaves were grind in the water and liquid was filtered to get clear liquid as shown in Figure 2, and the liquid used for finishing the textile fabric.

\subsection{Preparation the Extracted Solution from Dry Neem Leaf}

Leaf samples were washed using water to remove dust and particles. The leaves were separated from the stalk and dried in the ambient temperature for one week, after drying, the leaves were grinded into a powder by using mill, and the powder sample was kept in dark glass bottle.

The Neem powder were mixed with water at a ratio of one kilogram of powder to five liters of water, and mixed without heat or boil to get high concentration of Azadirachtin content, after that the liquid was filtered to get clear liquid which used for finishing the textile fabric, as shown in Figure 3.

\subsection{The Processing of Fabric Finishing, Using Solution Extracted from Green and Dry Neem Leaf}

The extracted solution from green and dry has been applied as coating directly to the surfaces of the fabric by using laboratory padding machine.

Textile fabric was immersed in the diluted extracted solution from green and dry Neem leaf at room temperature, the fabric picks up from the solution set to be $(2 \%-5 \%)$, by adjust the squeezer system.

The color of solution from green Neem leaf was light but the color of solution

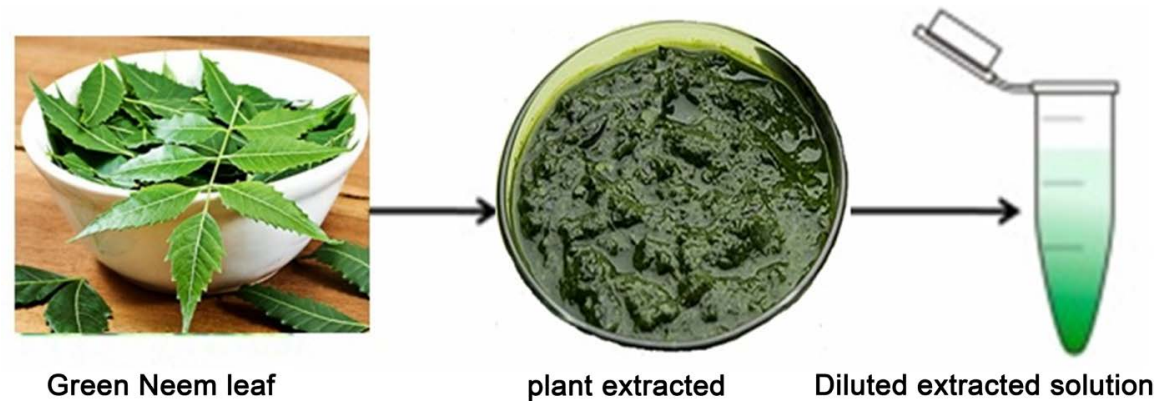

Figure 2. Diluted extracted solution from green Neem leaf.

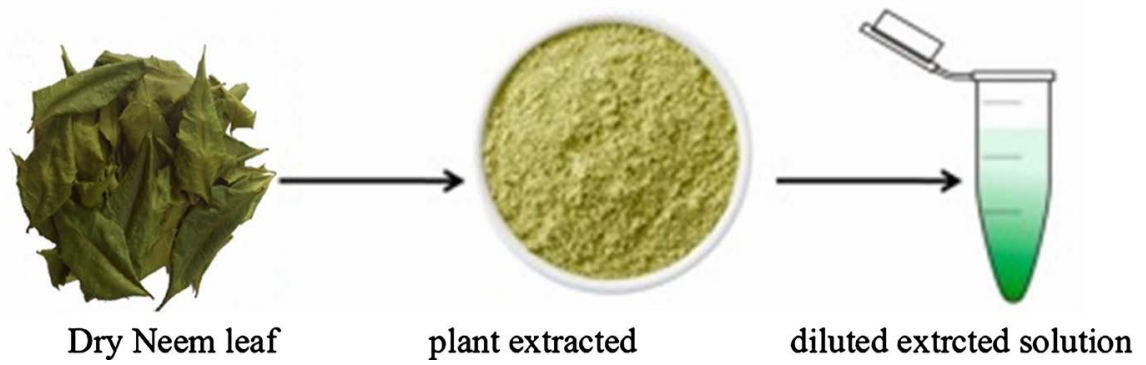

Figure 3. Diluted extracted solution from dry Neem leaf. 
from dry Neem leaf was dark, the color of solutions will affect certainly on the color of treated fabric.

\subsection{Testing the Mosquito Repellency by Effect of Fabric Finishing with Solution of Extracted Neem}

Figure 4 shows the instrument used for evaluation the mosquito repellency by the effect of fabric finishing with solution of extracted Neem.

Three samples of fabric were used, control fabric sample without finishing, fabric sample finished with extracted solution from green Neem leaf, and fabric sample finished with extracted solution from dry Neem leaf. The tested samples of fabric were placed in the instrument from the right side of the tube, and in the left side, a wet cotton swab as medium neutral was placed.

The mosquitoes were placed in the middle slot of the tube of the instrument, the slot and box were closed and light of instrument was off. After 20 minutes, the box was opened, and numbers of insects were counted, either that moved to the right direction from the middle of the tube to the solution extracted, or that moved to the left direction to wet cotton swab, as shown in Table 1.

\section{Results and Discussion}

\subsection{Effect of the Types Fabric Finishing on the Mosquitoes Repellent}

It is clear from Table 1 that the percentage of mosquitoes moved to the direction

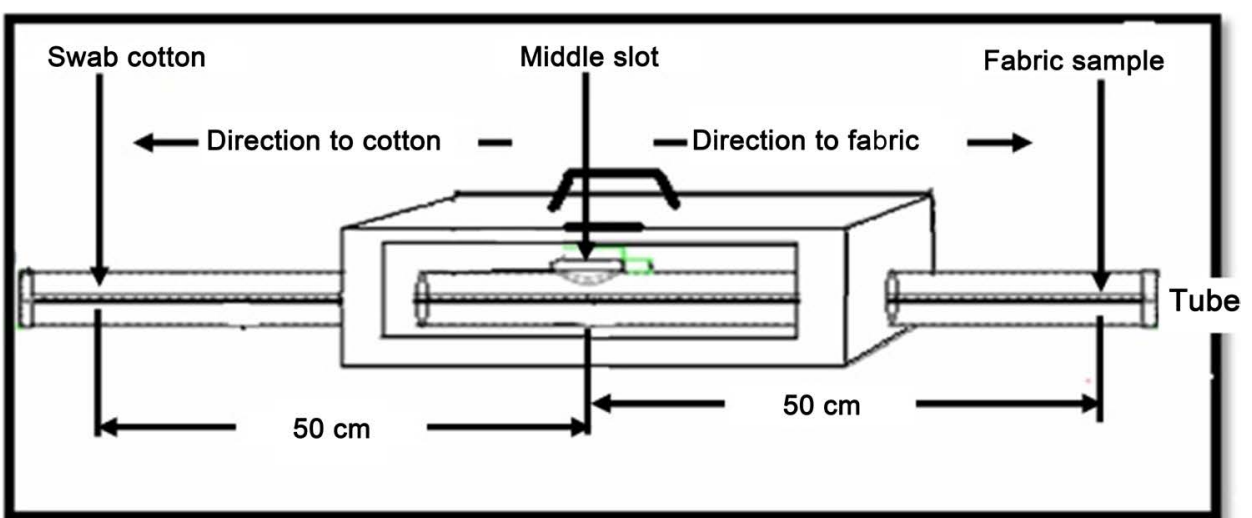

Figure 4. Instrument for evaluation mosquito repellency.

Table 1. Effect of fabric finishing by using the extracted green and dry solution of Neem leaf, on the repel mosquito.

\begin{tabular}{ccccc}
\hline Samples & $\begin{array}{c}\text { Percentage of } \\
\text { mosquitoes } \\
\text { moved to samples }\end{array}$ & $\begin{array}{c}\text { Percentage of } \\
\text { mosquitoes moved } \\
\text { to wet cotton }\end{array}$ & $\begin{array}{c}\text { Percentage } \\
\text { of repellent }\end{array}$ & $\begin{array}{c}\text { Percentage } \\
\text { of attraction }\end{array}$ \\
\hline Control fabric sample & 100 & 0 & 0 & $100 \%$ \\
$\begin{array}{c}\text { Fabric finished with extracted } \\
\text { solution from green Neem Leaf } \\
\text { Fabric finished with extracted } \\
\text { solution from dry Neem Leaf }\end{array}$ & $20 \%$ & $80 \%$ & $80 \%$ & $20 \%$ \\
\hline
\end{tabular}


of the control fabric sample was $100 \%$, i.e., the percent of mosquitoes repellent for control fabric sample is (zero \%), and the percent of mosquitoes attraction for control fabric sample is $100 \%$.

The percentage of mosquitoes moved to the direction of the fabric finished with extracted solution from green Neem Leaf was $20 \%$, \%, i.e., the percent of mosquitoes repellent for fabric finished with extracted solution from green Neem Leaf is $80 \%$, and the percent of mosquitoes attraction for fabric finished with extracted solution from green Neem Leaf is $20 \%$.

The percentage of mosquitoes moved to the direction of the fabric finished with extracted solution from dry Neem Leaf was $40 \%$, \%, i.e., the percent of mosquitoes repellent for fabric finished with extracted solution from dry Neem Leaf is $60 \%$, and the percent of mosquitoes attraction for fabric finished with extracted solution from green is $40 \%$.

To increase the efficiency of repellent, the concentration of Neem should increase for both of dry and green Neem in extracted solution.

From all of above, the finishing fabric with Neem leaf has a significant effect on repel mosquitoes.

\subsection{Effect of the Finishing Types on the Fabric Properties}

The researcher carried out some experiments on the finished samples to study the effect of the finishing on the fabric properties and evaluate the end use of the samples, the following tests carried out on plain weave fabric $100 \%$ cotton, as shown in Table 2.

\subsubsection{Weight of Fabric}

Figure 5 shows the weight of control fabric sample was $88.8 \mathrm{~g} / \mathrm{m}^{2}$, after finishing the weight of fabric increased, the weight of fabric finished with the extracted solution green Neem leaf was $93.2 \mathrm{~g} / \mathrm{m}^{2}$, in the other side the weight of fabric finished with the extracted solution dry Neem leaf was $96.8 \mathrm{~g} / \mathrm{m}^{2}$.

The increment of weight for finished fabric with dry Neem leaf was due to the more concentration substance of Neem in the extracted solution.

Table 2. Fabric properties after finishing by using the extracted solution from green and dry Neem leaf.

\begin{tabular}{cccc}
\hline & \multicolumn{3}{c}{ Types of fabric finishing } \\
\cline { 2 - 4 } Fabric Properties & $\begin{array}{c}\text { Control fabric } \\
\text { sample }\end{array}$ & $\begin{array}{c}\text { Fabric finished with } \\
\text { solution green Neem Leaf }\end{array}$ & $\begin{array}{c}\text { Fabric finished with } \\
\text { solution dry Neem Leaf }\end{array}$ \\
\hline Weight $\left(\mathrm{g} / \mathrm{m}^{2}\right)$ & 88.8 & 93.2 & 96.8 \\
Air Permeability $\left(\mathrm{cm}^{3} / \mathrm{cm}^{2} / \mathrm{s}\right)$ & 35 & 33.3 & 34.2 \\
Stiffness & 52.2 & 49.8 & 53.4 \\
Thickness $(\mathrm{mm})$ & 0.3 & 0.33 & 0.32 \\
Drapeability & 56.64 & 55 & 49.4 \\
Crease Recovery Angle & 150 & 180 & 130 \\
\hline
\end{tabular}




\subsubsection{Air Permeability}

Figure 6 shows the air permeability of control fabric sample was $35 \mathrm{~cm}^{3} / \mathrm{cm}^{2} / \mathrm{s}$, but after finishing with green and dry Neem, the air permeability of fabric decreased. The air permeability of treated fabric with the extracted solution of green Neem leaf was $33.3 \mathrm{~cm}^{3} / \mathrm{cm}^{2} / \mathrm{s}$, and the air permeability of finished fabric with the extracted solution dry Neem leaf was $34.2 \mathrm{~cm}^{3} / \mathrm{cm}^{2} / \mathrm{s}$.

The decrement of air permeability of fabric after finishing with dry and green Neem leaf comparing with the control fabric sample was due to the increment of non fibrous materials during finishing processing.

\subsubsection{Fabric Stiffness}

Figure 7 shows the stiffness index of control fabric sample was 52.2 but after

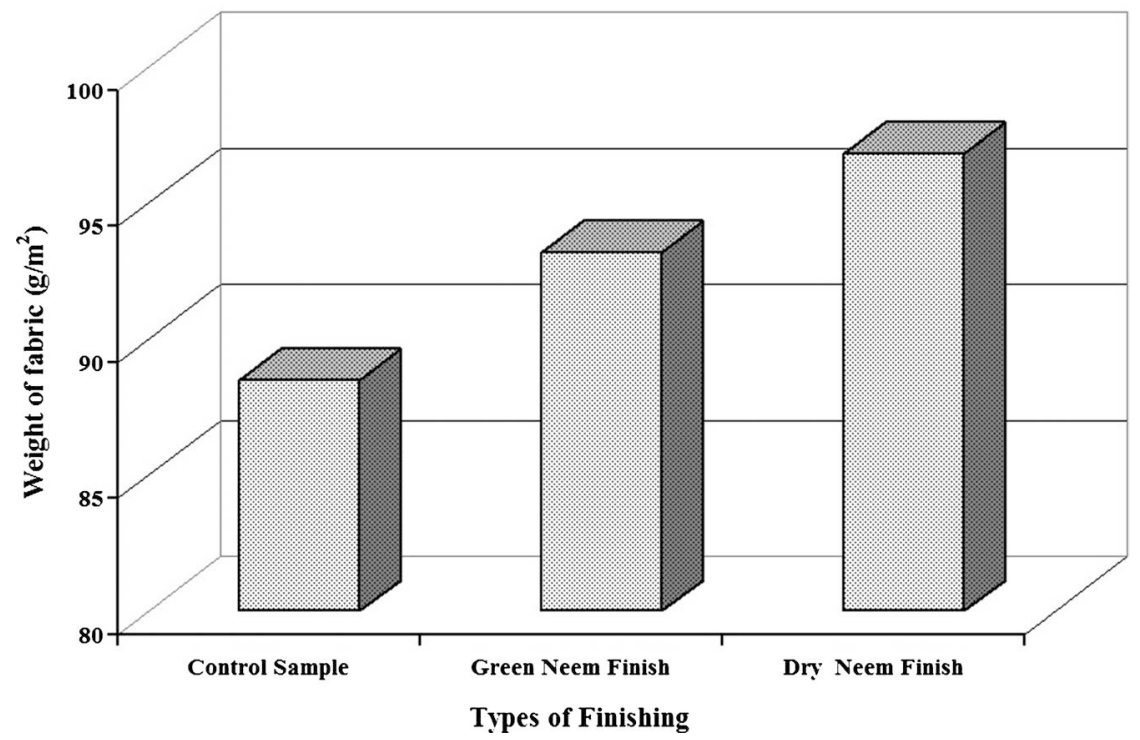

Figure 5. Effect of types of finishing on the weight of fabric.

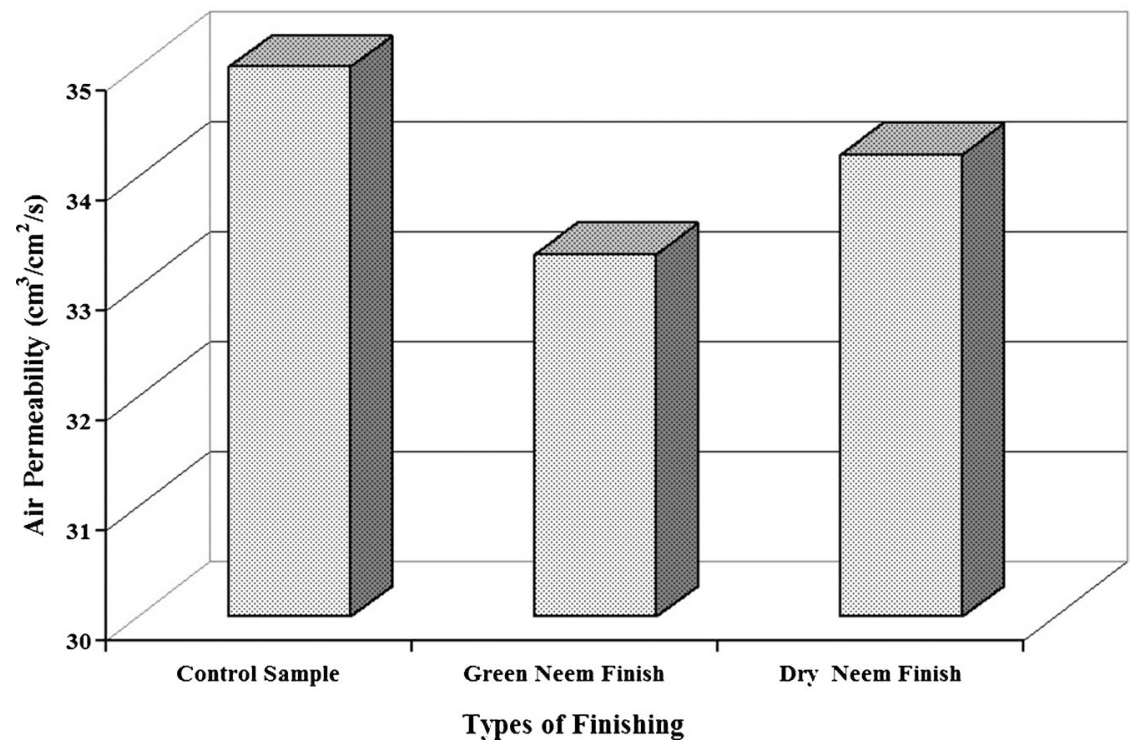

Figure 6. Effect of types of finishing on air permeability. 
finishing with green and dry Neem, the stiffness of fabric changed.

The stiffness of fabric treated with the extracted solution green Neem leaf was 49.8 , in the other side the stiffness of fabric treated with the extracted solution dry Neem leaf was 53.4 .

The increment of stiffness index for the treated fabric with dry Neem leaf was due to the more concentration substance of Neem in the extracted solution which leads to more non fibrous materials in the textile fabric.

\subsubsection{Thickness of the Fabric.}

Figure 8 shows the thickness of control fabric sample was $(0.3 \mathrm{~mm})$, after finishing the thickness of fabric increased.

The thickness of finished fabric with the extracted solution green Neem leaf

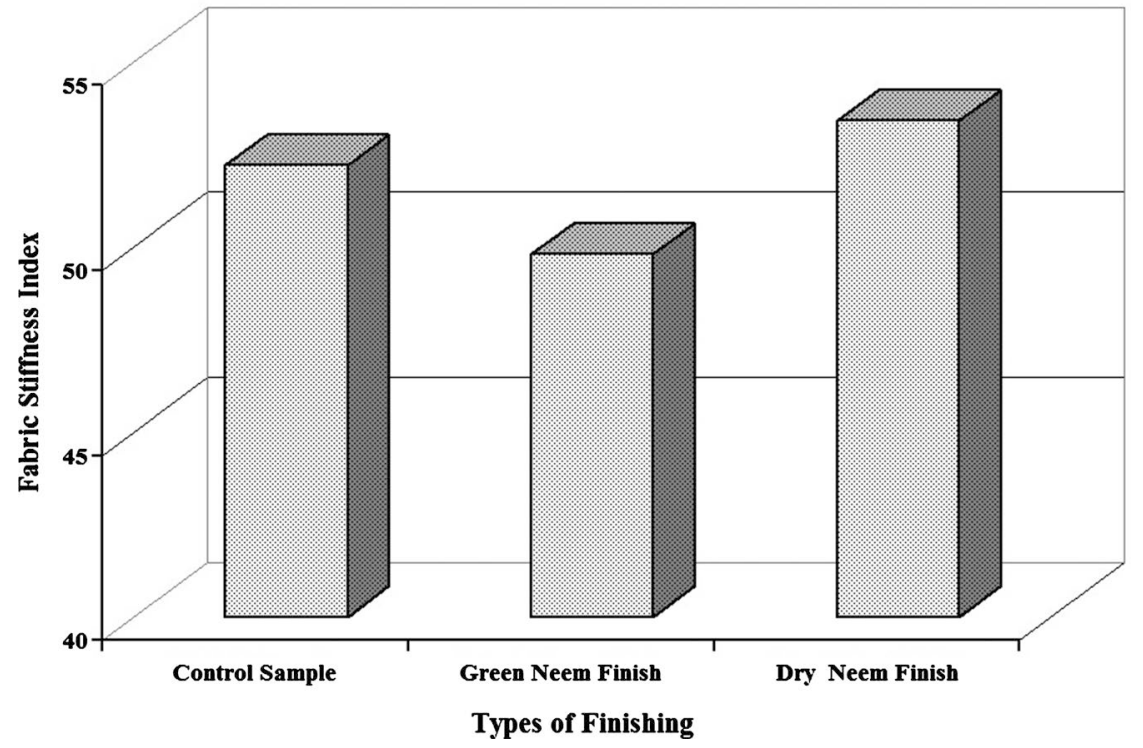

Figure 7. Effect of types of finishing on fabric stiffness.

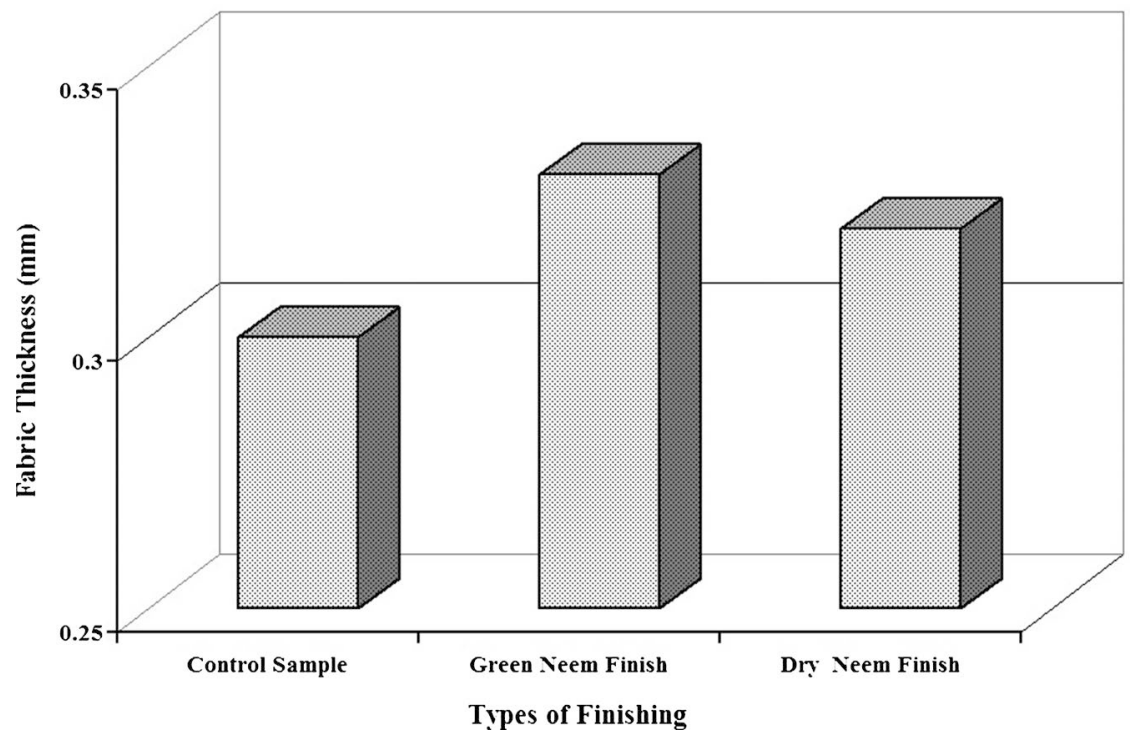

Figure 8. Effect of types of finishing on thickness of fabric. 
was $(0.33 \mathrm{~mm})$ and the thickness of treated fabric with the extracted solution dry Neem leaf was $(0.32 \mathrm{~mm})$.

The increment of the fabric thickness after finishing with dry Neem leaf was due to the non fibrous materials after finishing.

\subsubsection{Drapeability}

Figure 9 shows the drapeability index of control fabric sample was (56.64), after finishing the drapeability of decreased.

The drapeability index of finished fabric with the extracted solution green Neem leaf was (55\%) and the drapeability index of treated fabric with the extracted solution dry Neem leaf was (49.4\%).

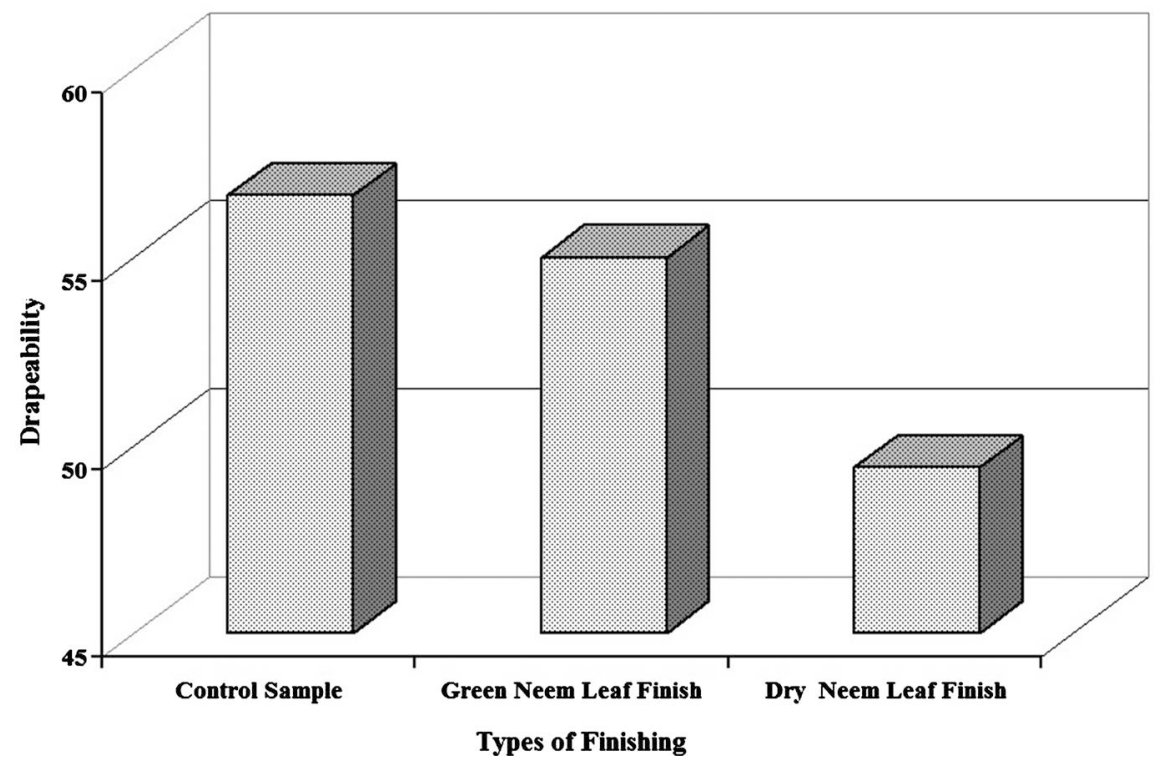

Figure 9. Effect of types of finishing on fabric drapeability.

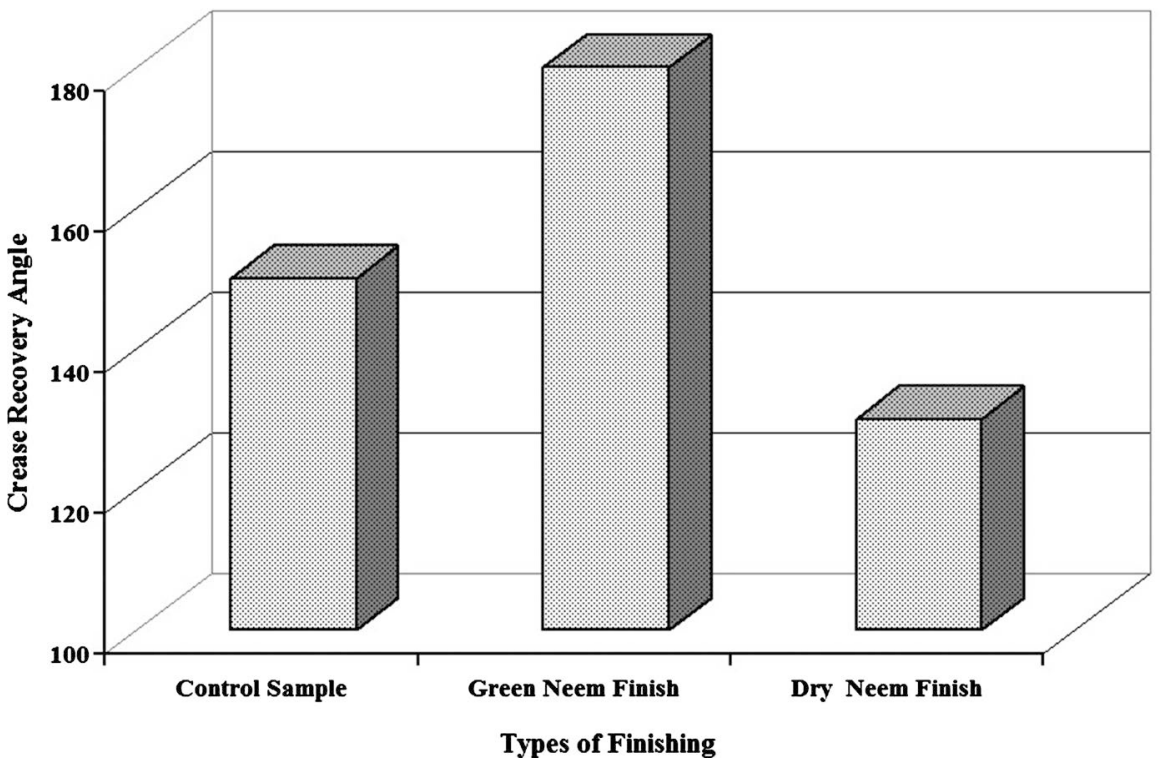

Figure 10. Effect of types of finishing on the fabric crease recovery angle. 
The drapeability index after finishing shows that the drape of fabric improved after finishing with both dry and green Neem leaf.

\subsubsection{Crease Recovery Angle of Fabric}

Figure 10 shows the crease recovery angle of fabric control fabric sample was (150), after finishing the crease recovery angle changed depending on the finished type.

The crease recovery angle of finished fabric with the extracted solution green Neem leaf was (180) and the crease recovery angle of treated fabric with the extracted solution dry Neem leaf was (130).

The crease recovery angle of treated fabric with the extracted solution green Neem was better than crease recovery angle of treated fabric with the extracted solution dry Neem, because the increment of non fibrous due to using dry Neem leaf, which lead to be stiff.

\section{Summary}

1) The fabric finished by using green Neem leaf has the ability to repel $80 \%$ of mosquitoes, and the fabric finished by using dry Neem leaf has the ability to repel $60 \%$ of mosquitoes.

2) The finishing of fabric with the extracted solution green and dry Neem leaf has a significant effect on the fabric properties.

3) The extracted solution from green and dry Neem leaf can be used as spray to repel mosquitoes

4) Being eco-friendly for the textile finishing is top urgent.

\section{Conflicts of Interest}

The author declares no conflicts of interest regarding the publication of this paper.

\section{References}

Abu Abdoun, A. I. (2000). Wonder Tree. Sharjah: University of Sharjah.

Al-Mohmadi, R. M. A., \& Al-Khalef, A. A. K. (2008) Parasites Associated with Sarcophaga haemorrhoidalis Pupae in Jeddah City. Bulletin of Pure \& Applied Sciences, 26, 87-89.

Alouani, A., Rehimi, N., \& Soltani, N. (2009). Larvicidal Activity of a Neem Tree Extract (Azadirachtin) against Mosquito Larvae in the Republic of Algeria. Jordan Journal of Biological Sciences, 2, 15-22.

Girish, K., \& Shankara Bhat, S. (2018). Neem-A Green Treasure. Electronic Journal of Biology, 4, 102-111.

https://www.researchgate.net/publication/264657953_Neem_-_A_Green_Treasure

Hatem, A. N., Mansour, N., \& Akbar, M. M. (2011) Effect of Some Aquatic Plant Extracts and Dry Powders on Some Aspects of the House Fly Insect. Iraq: Department of Life Sciences, Faculty of Science, University of Basra.

Michel, H. (1993). Encyclopedia of Medicinal Plants. Beirut: Lebanon Publishing Library.

Mridha, M. A. U., \& Al-Suhaibani, N. A. (2014). Prospect of Neem Plantation at Arafat, 
Saudi Arabia. Current World Environment, 9, 81-86.

http://www.cwejournal.org/?p=5624

https://doi.org/10.12944/CWE.9.1.12

Nassif, M. M. A. M. O. (1999) The New Technique to Protect the Environment. Alexandria: Textile Information Bulletin, Textile Industry Support Fund, Documentation and Advertising Center.

Nassif, M. M., \& Mona, A. M. O. (2004). Technology of Preparations Dyeing and Printing. Textile Industry Support Fund, Textile Development Center, Technical Training Programs.

Qaisi, H. (1998). Dictionary of Medicinal Herbs and Plants. Beirut: Dar al-Kutob.

Sheta, A. F., \& Nader, K. S. M. (1999). Economy and Consumption of Apparel. Makkah: Dar Al-Thaqafa for Printing.

Thilagavath, K., Rajendrakumar, \& Rajendran, R. (2005). Development of Ant of Textile Antimicrobial Finishes from Plant Species. Express Textile. 